\title{
Responses to Stretch and the Effect of Pull on Propagation in Non-Striated Muscles of Golfingia (= Phascolosoma) and Mustelus
}

\author{
C. LADD PROSSER, C. L. RALPH AND WM. W. STEINBERGER \\ Marine Biological Laboratory, University of Illinois, U. S. Department \\ of Agriculture, and University of Michigan ${ }^{1,2}$
}

In the short-fibered non-striated probascis retractor of phascolosoma (Golfingia gouldii) ${ }^{3}$ conduction is entirely by intrinsic nerve fibers. Evidence for nerve conduction is: velocity of propagation ( 1.3 and $0.3 \mathrm{~m} /$ second for fast and slow responses, respectively), abundance of nerve fibers, block by nerve-blocking drugs, failure of propagation after nerve degeneration, and detection of nerve impulses ahead of muscle responses (Prosser and Melton, '54). Conduction in other non-striated postural muscles of invertebrates appears also to be by nerves. In vertebrate visceral smooth muscle, in contrast, conduction is from fiber to fiber independently of nerves and is very slow (few centimeters per second) (Bozler, '48, Prosser and Sperelakis, '56). In the circular intestinal muscle of the cat, conduction can pass a region clamped to prevent mechanical pull, it can occur under such tension that shortening is prevented, and mechanical and electrical responses can be partly dissociated by drugs (Sperelakis and Prosser, '59); hence mechanical pull appears unnecessary for muscle activation. However, some smooth muscles are stimulated by stretch, even in the absence of nerves and myenteric refiexes (e.g., chick amnion, Evans and Schild, '56) and many smooth muscles show increased excitability when they are extended (e.g., taenia coli of guinea pig, Bulbring, '54).

Is conduction in visceral smooth muscle of lower vertebrates and invertebrates independent of nerves? What is the relation between mechanical pull and conduction in muscles which are stimulated by stretch?

\section{MATERTALS AND METHODS}

External recording was by low-resistance wicks and silver-silver chloride electrodes connected to a high-gain amplifier. Mechanical activity was detected by an RCA transducer or by a Grass strain gauge. Most of the external recording was displayed on a Grass polygraph fed by a chopper amplifier. Mechanical stretches and releases were applied by a magnetic device which could deliver a pull of a predetermined number of millimeters at a rate of $1 \mathrm{~mm}$ per msec. Intracellular recording was with microelectrodes by methods given in the preceding paper for the proboscis retractor of Golfingia, (Prosser and Sperelakis, '59).

Two other muscles were used besides the proboscis retractor of Golfingia. The intestine of Golfingia spirals around a thin muscle, the spindle (fusiform) muscle or intestinal retractor (Andrews, 1890). The ascending loop of the intestine forms a helix around this muscle and is attached to it, while the descending loop follows the ascending one in its coils, but it not attached to the muscle. The spindle muscle originates in the body wall near the anus and terminates at the region of the intestine where the ascending loop begins.

\footnotetext{
${ }^{1}$ Gratitude is expressed to $\mathrm{Mr}$. Russell Close who constructed and helped us employ the instrument used for quick stretch and release in many of the experiments.

2 Supported in part by NIH contract with MBL.

${ }^{3}$ Since an extensive experimental literature concerns the New England sipunculid, now known as Golfingia, formerly Phascolosoma (Fisher, '52), the name phascolosoma is here adopted as a common name.
} 
No connection with the cerebral ganglion or the ventral nerve cord could be found. The muscle is so small that most electrical recording was done under mineral oil.

The mesentery of the smooth dogfish Mustelus canis contains a sheet of smooth muscle which pulls the spiral valve of the upper intestine toward the dorsal body wall (Cannon, '08). Rhythmic contractions have been noted in response to stretch; adrenaline, acetylcholine and pituitrin elicit contractions (McKay-Sawyer, '33). Strips of mesenteric muscle were isolated in dogfish saline containing urea (Babkin et al., '33).

\section{RESULTS}

The spindle muscle (intestinal retractor) of Golfingia

When the spindle (fusiform) muscle was stimulated electrically, external re- cording showed complex action potentials, mainly fast components. Sometimes a single shock initiated repetitive bursts of potentials, each burst associated with separate contractions. On repetitive stimulation at a low frequency $(0.1 /$ second ) the muscle tended to follow without either the fatigue or facilitation seen in the proboscis retractor. The velocity of conduction, as measured by dual channel recordings from two pairs of electrodes, was slow - average $0.73 \mathrm{~cm} /$ second (fig. $1 \mathrm{a}$ ).

The excitability of the spindle muscle varied with stretch; when allowed to hang slack it was not readily excited; when under tension it was more readily stimulated either electrically or by touching with a glass rod (fig. 2 a-c). The electrical response was more persistent (repetitive) when taut than when relaxed. Also when taut, the muscle often showed rhythmic

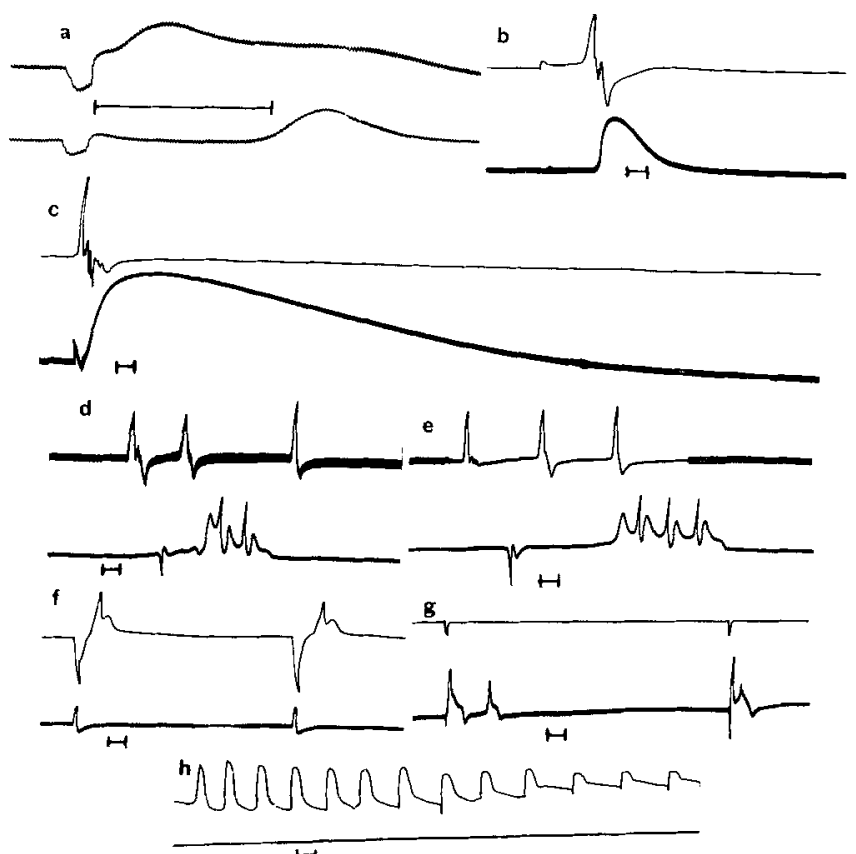

Fig. 1 Responses of spindle muscle. Time marks one second. a, action potentials in response to shock recorded simultaneously from two regions $15 \mathrm{~mm}$ apart for velocity measurement; b, c, electrical response above, mechanical below, responses to stretch, $b$ before and $c$ after 10 minutes soaking in tetracaine $10^{-4} ; \mathrm{d}$; e, electrical responses recorded from two muscle regions connected by taut oil-soaked thread, upper record from segment receiving electrical stimulation, lower record from muscle on other side of thread; $f, g, h$, muscle coiled around glass rod to prevent movement, in $f$, upper record from portion of muscle on side of rod receiving stimulation, lower record from region on other side of rod, only stimulus artifact conducted, in $g$ stimulus applied on opposite side from $f$, in $h$, spontaneous activity on one side of rod (upper record) not transmitted to portion of muscle on opposite side (lower record). 


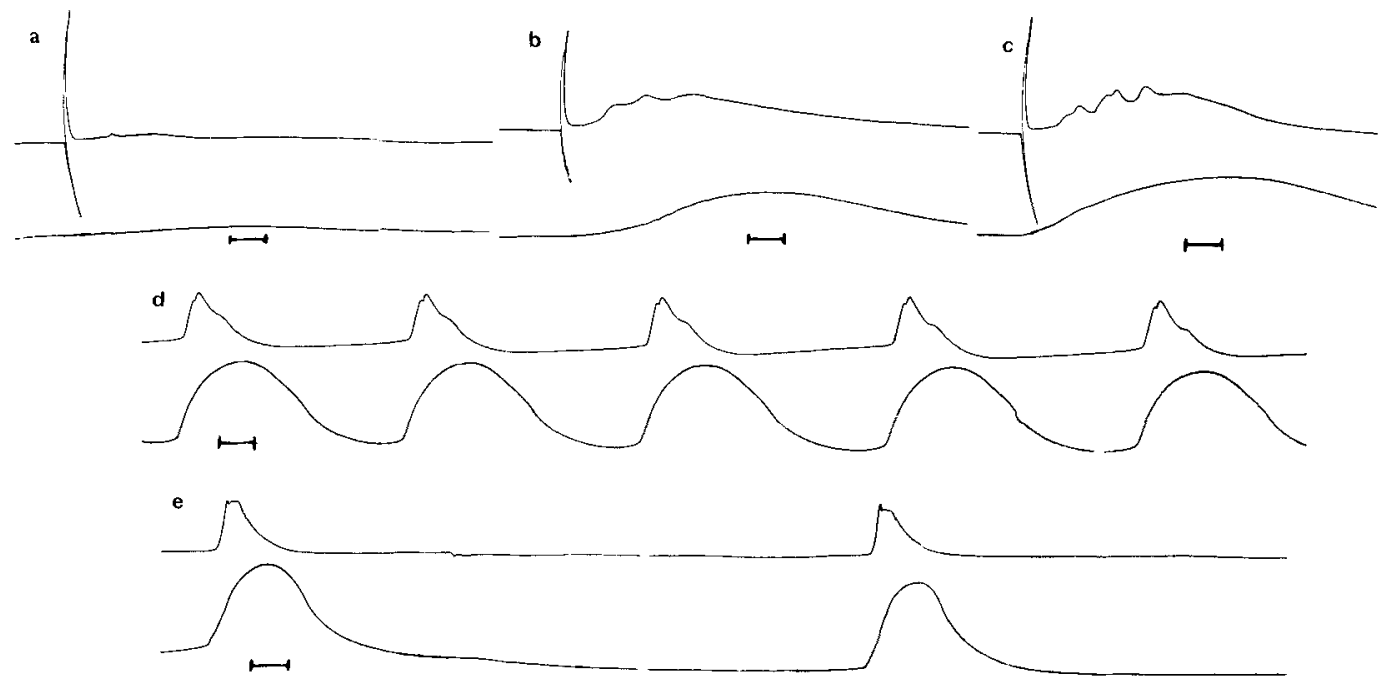

Fig. 2 Spindle muscle. Time records one second. a, b, c, action potentials above, contractions below in response to shocks, stimulus artifact initial downward deflection, response upward; a to $c$, increasing tension applied to muscle; $d$, e, spontaneous rhythms, electrical above, mechanical below, tension on muscle higher in $d$ than in $e$.

spontaneous activity at one per second to one per three seconds (fig. 2 d-e).

When a 2- to 4-cm length of the spindle muscle was quickly stretched by 1 to $4 \mathrm{~mm}$, it responded by an active contraction after a brief latency. The latency lengthened and the amplitude of contraction decreased as the stretch was diminished and a threshold amount of stretch was necessary to stimulate (fig. $3 \mathrm{~h}, \mathrm{i}, \mathrm{j}, \mathrm{k}$ ). Often a stretch well above threshold initiated rhythmic contractions (fig. 3a). Action potentials preceded and accompanied the mechanical responses to quick stretch and showed a velocity of a little less than $1 \mathrm{~cm}$ per second (fig. $3 \mathrm{~b}, \mathrm{c}$ ). If released during contraction, tension was redeveloped to nearly the level corresponding to the phase of contraction (fig. $3 \mathrm{~d}, \mathrm{e}, \mathrm{f}, \mathrm{g}$ ).

The very slow velocity of conduction, the sensitivity to tension and the active response to stretch suggest that propagation in the spindle muscle is by mechanical pull from fiber to fiber. To block mechanically, a muscle was wrapped around a 1-mm glass rod. Under conditions where no rotation of the muscle on the rod occurred, a contraction wave was conducted up to the block and no electrical or mechanical re sponse was seen beyond it (fig. $1 \mathbf{f}, \mathrm{g}, \mathrm{h}$ ). In other experiments, an oil-soaked thread was tied between two cut portions of a muscle. When the muscle and thread were taut so that pull could be transmitted through the thread and the muscle at one end was stimulated, electrical responses were obtained from muscle on both sides of the thread (fig. $1 \mathrm{~d}, \mathrm{e}$ ). If a short thread was tied between two points on a muscle so that a long mid-region hung loosely below, a response was obtained from the tensed portion beyond the thread but no response from the loose portion below the thread even though this region was nearer the stimulating electrodes. It is concluded that propagation in the spindle muscle is by mechanical pull from one region to the next.

The effect of stretch on the spindle muscle might be on muscle fibers or it might involve nerves or possibly an intrinsic reflex. Worms were injected with methylene blue, which stains nerves in the proboscis retractor very well. No connection of the muscle with the central nervous system was noted. A few nerve fibers were seen in the mesentery between the muscle and the intestine. In the center of the spindle muscle a core was stained with methylene blue. Histological sections showed this core to consist of coarse fibers which did not take a silver stain and which stained 


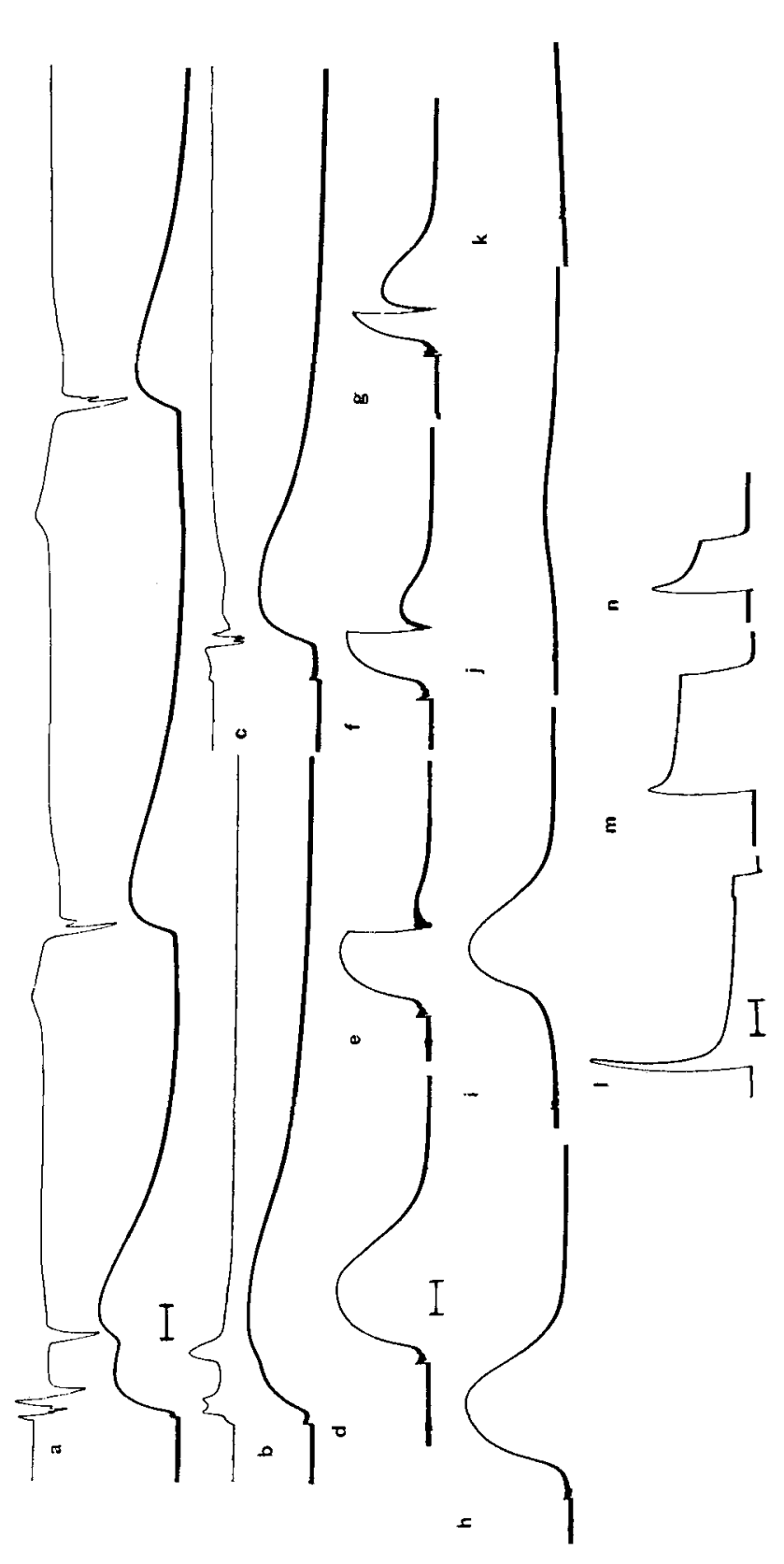

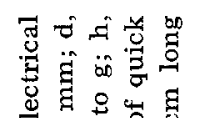

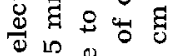
ن 舟 की ही 范 范 घี่

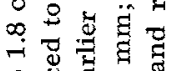
워

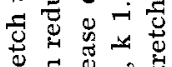
후월

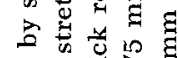
그을 .

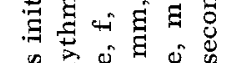
象

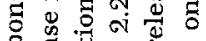

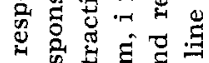
งิ

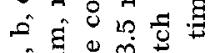

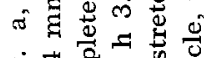

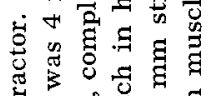
के के कु

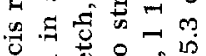

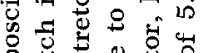

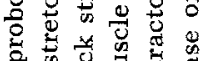

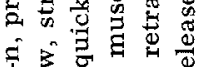
$\rightarrow$ 을 용

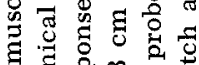

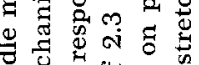

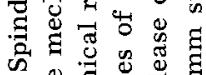
के ๙ั ช.

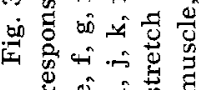


like the outer connective tissue sheath with Mallory's triple stain. Also, the core failed to stain with thionin or sudan black. It is concluded that the core is not nerve fibers but is probably connective tissue.

The proboscis retractor shows nerve degeneration and loss of conduction after several days in the refrigerator. When spindle muscles were similarly treated for 5 to 6 days they still responded to shock and stretch and showed relatively normal conduction. In some of these the central core failed to stain, in others it did stain with methylene blue.

The nerve-blocking drug tetracaine stops conduction in the proboscis retractor; a concentration of $10^{-4}$, applied locally, blocked in less than 15 minutes. When tetracaine at the same concentration was applied to the fusiform spindle muscle, there was no block at 30 minutes. When soaked in tetracaine the threshold was raised and responses could be stopped irreversibly at a concentration of $10^{-4}$ and reversibly at $10^{-5}$. After 10 to 15 minutes in $10^{-4}$ tetracaine the contraction time was lengthened from $1-1.5$ to $4-6$ seconds and the total duration of contraction from 8-10 seconds to $40-50$ seconds (fig. 1 b, c). Tetracaine can raise threshold and prolong contraction but local applications which block nervous conduction in the proboscis retractor do not block the spindle muscle. D-tubocurarine blocks the response of the proboscis retractor at the point of application (Prosser and Melton, '54). At the concentration of $10^{-4}$ it had no effect on the spindle muscle ( 30 minutes). Acetylcholine at $10^{-5}$ stimulated the muscle to contract.

Important evidence for nerve conduction in the proboscis retractor was observation of nerve impulses at the same velocity but well ahead of the muscle responses (Prosser and Melton, '54). Action potentials were recorded from the spindle muscle with high gain amplification and various sweep speeds of the oscilloscope. The responses were usually smooth, sometimes complex, much as when recorded with the ink-writer (fig. $4 \mathrm{a}, \mathrm{b}, \mathrm{d}, \mathrm{e}, \mathrm{f}$ ). There was no evidence of any nerve impulses ahead of the muscle response. If the central core were a nerve, some evidence of fast action potentials
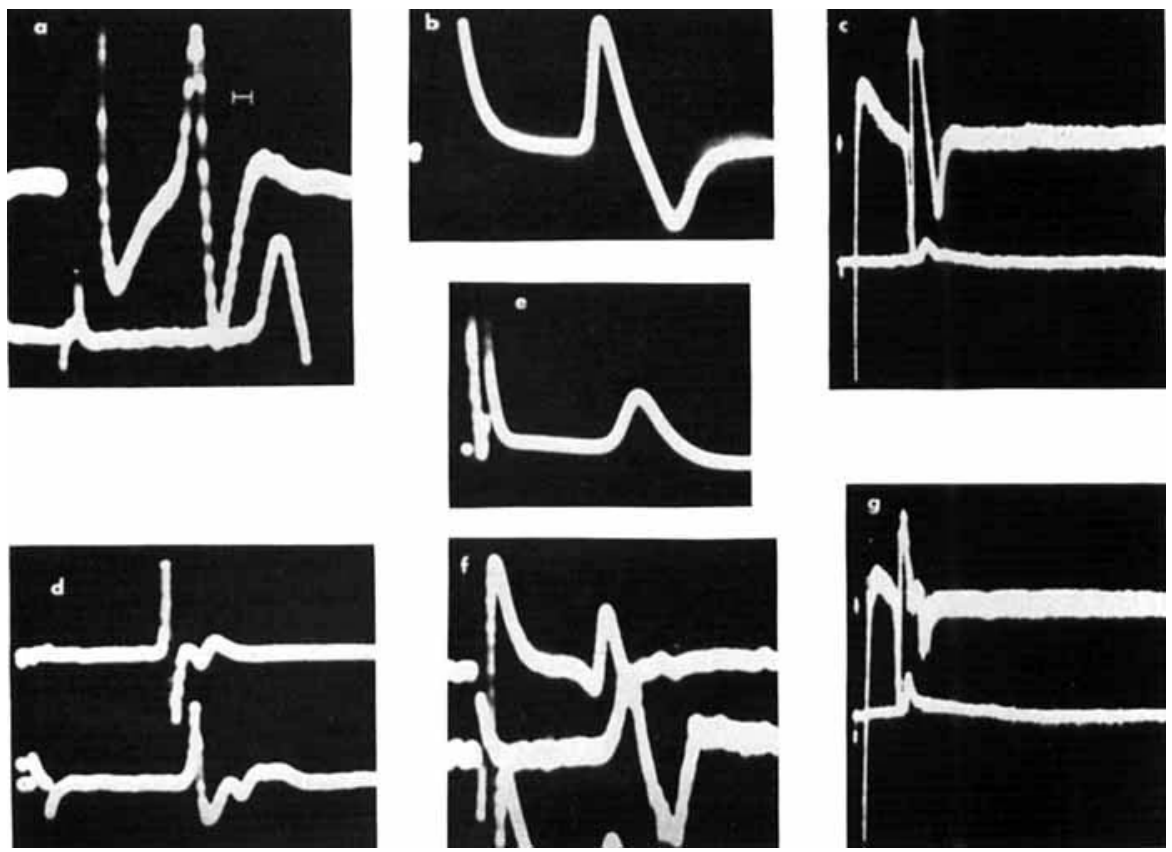

Fig. 4 Spindle muscle. Oscilloscope records of responses to shocks. a, b, d, e, f, external recording, $a, d, f$ simultaneous recording from two regions. $c, g$, externally recorded response upper beam, intracellular response lower beam. 
from it should have been found. The evidence from the histology, the effects of drugs, and the high-speed recording indicates that the response to stretch which mediates conduction in the spindle muscle resides in the muscle fibers and is not a nervous reflex.

Many attempts were made to record with microelectrodes from this muscle. Macerated muscles gave fiber dimensions of an average maximum width of 5.7-6 $\mu$ and length of 800-900 $\mu$. These fibers are a little narrower and much longer than those of the proboscis retractor. To penetrate them with microelectrodes proved very difficult. High resistance electrodes of various tip shapes were tried repeatedly with both rigid and floating manipulation. The largest "resting" potentials recorded were $10 \mathrm{mv}$ and few reliable action potentials were obtained. These were spikes without overshoot (fig. $4 \mathrm{c}, \mathrm{g}$ ). It is probable that the fiber membranes do not permit an adequate seal around a microelectrode tip.

\section{The proboscis retractor of Golfingia}

Evidence has been presented previously that propagation in the proboscis retractor is by nerves (Prosser and Melton, '54) and that many of the muscle fibers are dually innervated (Prosser and Sperelakis, '59).

When a proboscis retractor was stretched, there was initial elastic tension which declined rapidly to a value corresponding to the new length. There was no active response to the stretch but rather the muscle reacted to stretch much the same as a vertebrate striated muscle (fig. $3 \mathrm{l}, \mathrm{m}, \mathrm{n})$. Conducted impulses pass a region of mechanical block; hence pull is not necessary for propagation.

\section{The mesenteric muscle or spiral valve retractor of the dogfish}

This muscle consists of typical vertebrate smooth muscle fibers 2 to $3 \mu$ diameter and 0.1 to $0.18 \mathrm{~mm}$ long as measured from macerated tissue. The fibers are grouped in fasciculi, each about 0.1 to 0.2 mm wide. Strips about a half to two millimeters wide and 2 to $4 \mathrm{~cm}$ long were mounted in dogfish saline for stretch stimulation and for microelectrode recording, or in paraffin oil or moist air for external recording.

When stimulated with a single or with several suprathreshold shocks an initial fast spike or group of spikes appear on an external electrical record, then a train of smaller spikes as contraction starts (fig. 5 a, c, 7 a, b). Contraction may be maintained for from one half minute to several minutes with very little electrical activity, but as relaxation begins, increased electrical activity is noted (fig. $5 \mathrm{~b}, \mathrm{~d}, \mathrm{e}, \mathrm{f}$ ). Shocks applied during the maintained contraction elicit no apparent response. Much variability occurred, some preparations showed more rapid relaxation than others and some showed continued action potentials during contraction and not during relaxation. Some preparations showed relatively brief slow potentials and these could be repeated at intervals greater than 5 seconds. Long recovery periods (about 10 minutes) were necessary between successive large contractions showing multiple action potentials.

With two pairs of recording electrodes, velocities were measured at an average of $1.1 \mathrm{~cm} /$ second at $23^{\circ} \mathrm{C}$ (fig. $6 \mathrm{e}$ ). This is of the same order as the velocity of mammalian smooth muscle $(3$ to $5 \mathrm{~cm} /$ second at $37^{\circ} \mathrm{C}$ ) but much slower than the nerve transmission of the phascolosoma proboscis retractor and faster than the stretch conduction of the spindle muscle. Responses of the dogfish mesenteric muscle were better under slight tension, but were obtained irrespective of whether the muscle was taut or loose.

When subjected to a quick stretch, a response was initiated which resembled that to a shock. A burst of spikes was recorded and then an active contraction which lasted for more than 1.5 minutes and with little maintained electrical activity (fig. 6 a, b). Sometimes repetitive action potentials appeared during relaxation (fig. 6 a, b). Responses were graded according to the stretch. Contractions were steady and only rarely repetitive as in the spindle muscle. If during a contraction, tension was suddenly released, there was redevelopment of tension to near the pre-release level (fig. $6 \mathrm{~b}, \mathrm{c}$ ). If release occurred near the beginning of relaxation, there was little or no redevelop- 


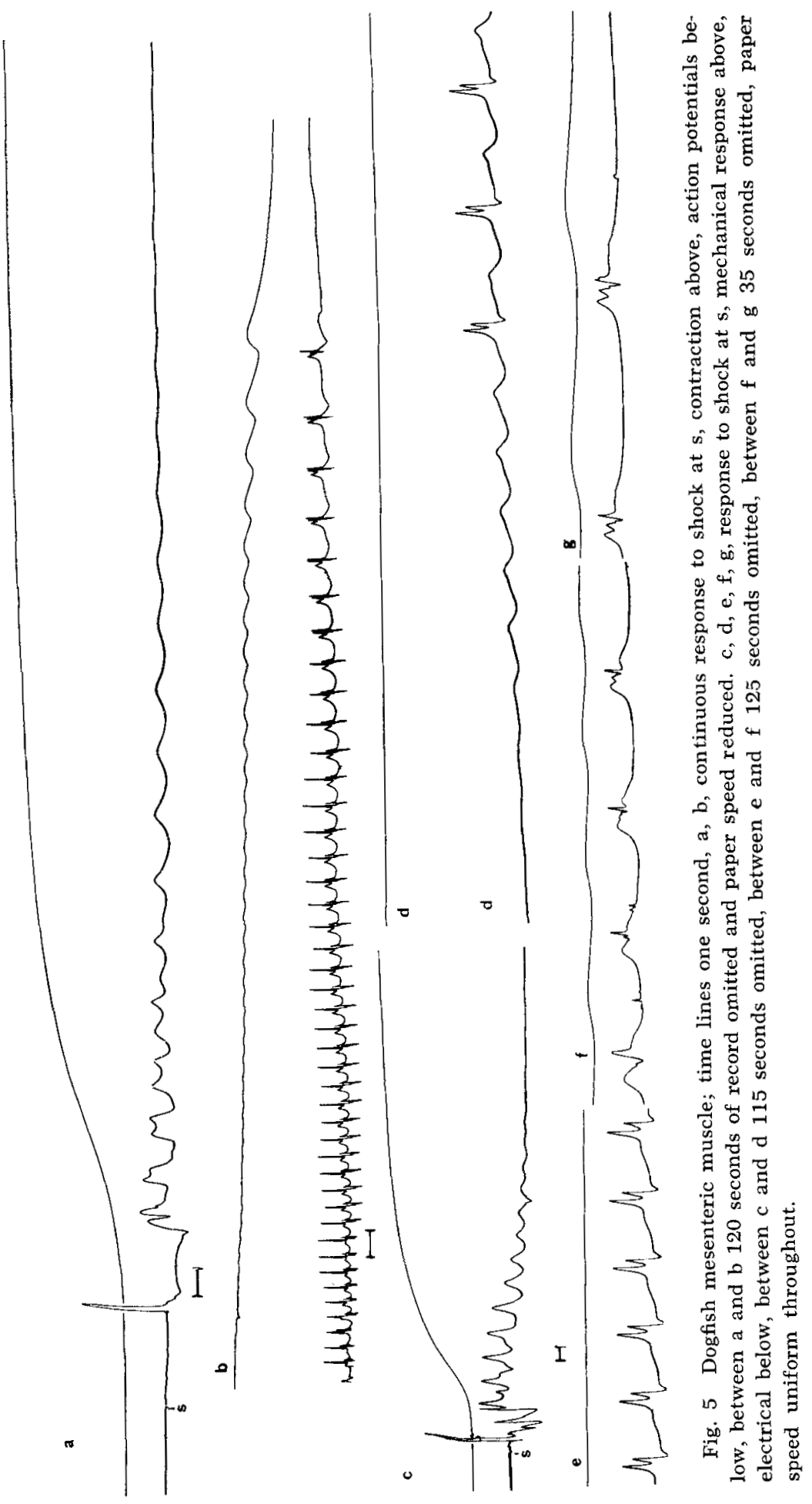




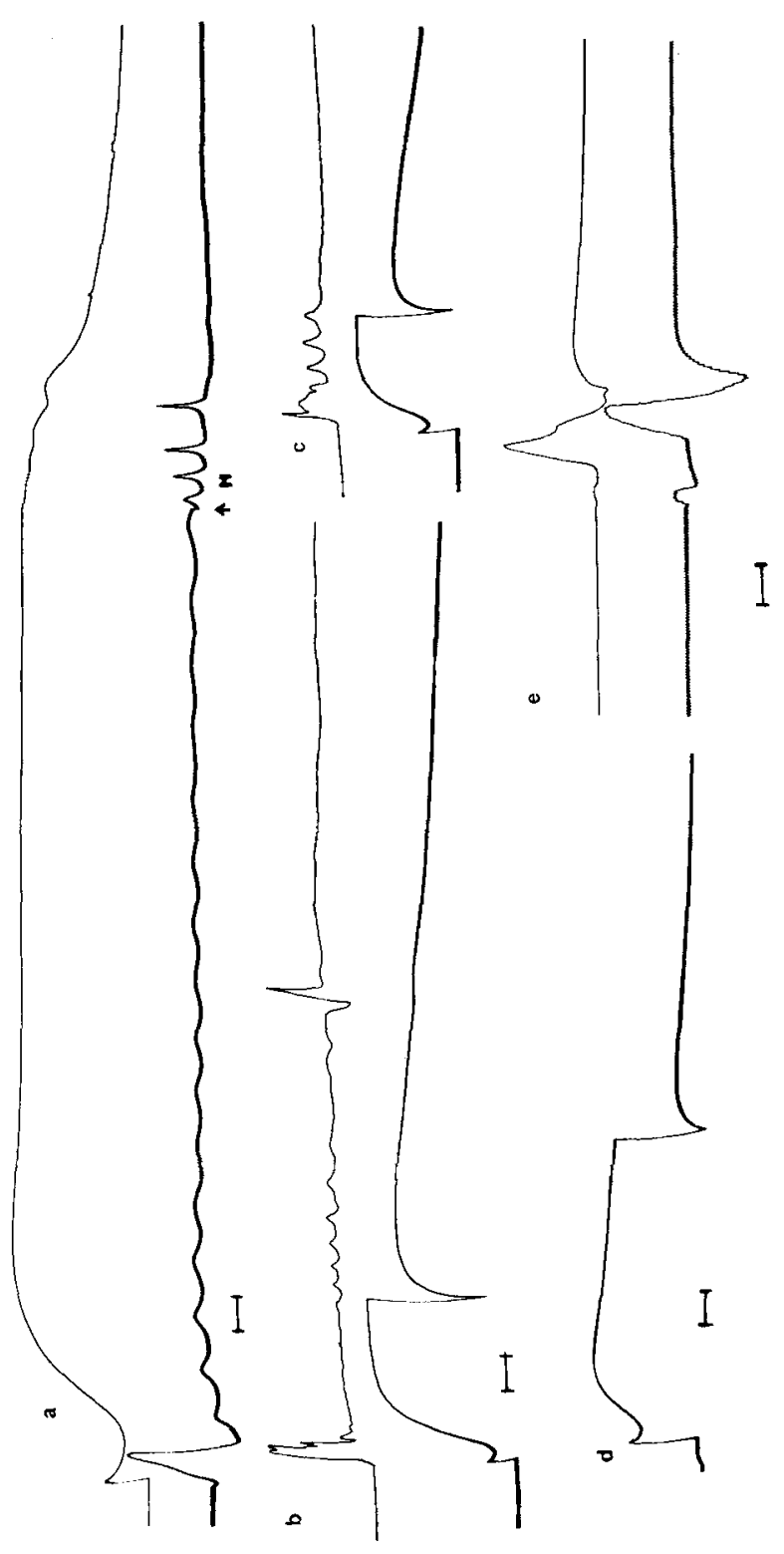

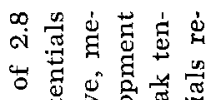

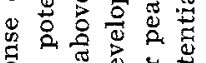

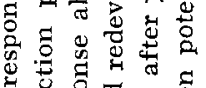

\%

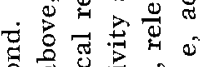

क

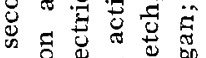

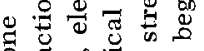

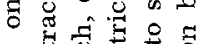

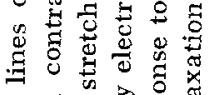

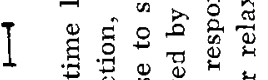

元

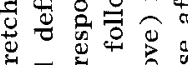

की

यद 300

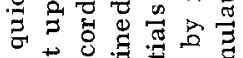

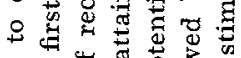

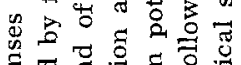

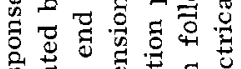

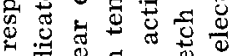

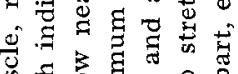

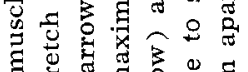

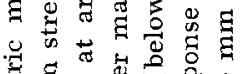

घ छ

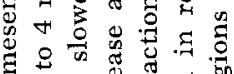

ป

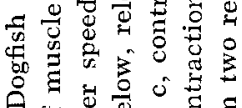

А

-

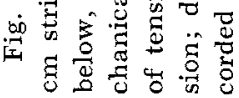




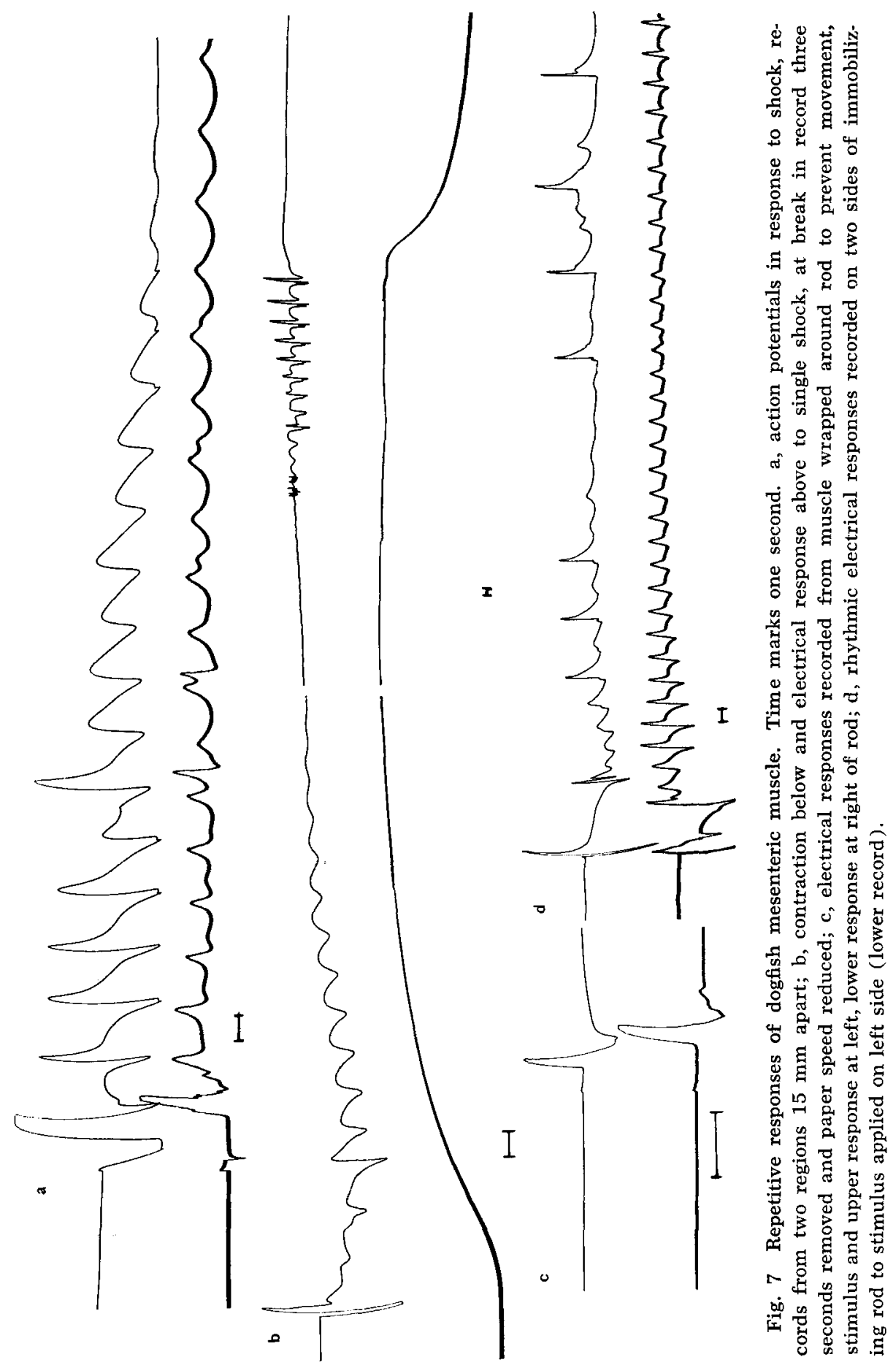


ment of tension (fig. 6 d). Apparently the active state persists until shortly before relaxation.

When a strip was immobilized in the middle by winding around a small glass rod, good propagation at the appropriate velocity was observed from one side to the other (fig. $7 \mathrm{c}, \mathrm{d}$ ). Propagation does not, therefore, require mechanical pull, although stretch can stimulate the muscle.

After two days in saline in the refrigerator, good conducted responses were still obtained. D-tubocurarine at $10^{-4}$ did not block conduction, nor did tetracaine at $10^{-4}$ applied for some 20 minutes. Gamma-amino-butyric acid at $10^{-4}$ to $10^{-5}$ prolonged contractions, enhanced the electrical responses and tended to make them repetitive. Stimulation by acetylcholine and by adrenaline has been reported previously (McKay-Sawyer, '33).
Staining with methylene blue revealed scattered thin nerve fibers, presumably autonomic ones. Ganglion cells were not seen. Action potentials were recorded by external electrodes at high gain and fast oscilloscope sweep. Responses were smooth or multiple and showed no evidence of nerve impulses ahead of the muscle response (fig. 8, c, h, i). In this respect they resemble responses of mammalian deganglionated intestinal muscle rather than the intact ureter (Prosser, Smith and Melton, '55; Prosser and Sperelakis, '56).

From the velocity, the insensitivity to tetracaine, the scarcity of nerves, the absence of nerve spikes ahead of muscle potentials, and the propagation through a mechanical block, it is concluded that propagation in the dogfish mesenteric muscle is independent of nerves and of mechan-
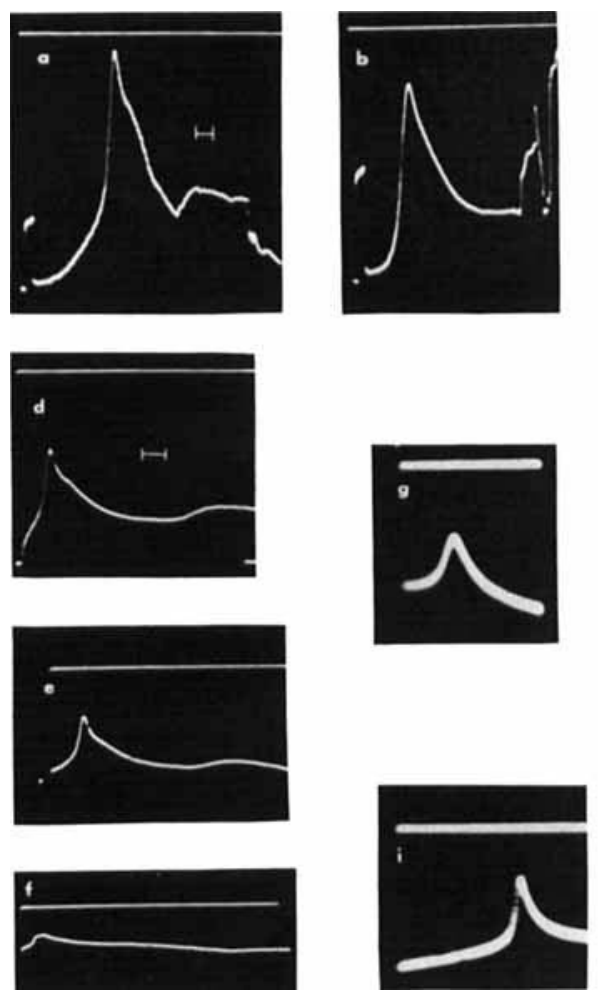
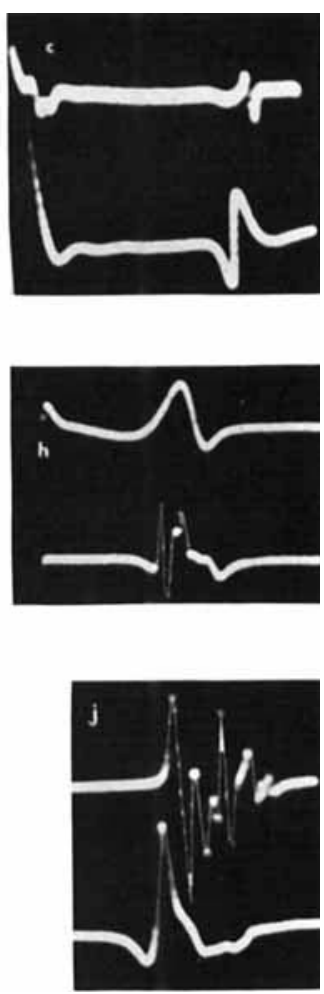

Fig. 8 Oscilloscope records from dogfish mesenteric muscle, time record (a, d) 0.1 second; $\mathrm{a}, \mathrm{b}$, intracellular responses to shock, resting potential $48 \mathrm{mv}$ in each; $\mathrm{c}, \mathrm{h}, \mathrm{i}$, externally recorded responses at two points to shock stimuli; $d, e, f$, series of intracellular responses to shocks as recorded resting potential declined, initial resting potential (d) $39 \mathrm{mv}$; $\mathrm{g}, i$, intracellularly recorded potentials during a maintained tension, resting potential $32 \mathrm{mv}$. 
ical pull but is, like that of mammalian smooth muscle, from muscle fiber to fiber.

Microelectrodes were relatively easily inserted into the dogfish smooth muscle. Despite the small fiber diameters, many penetrations yielded high resting potentials. The average of 24 measurements was $70 \mathrm{mv}$ with a range of 32 to $75 \mathrm{mv}$. This is higher than is usually recorded from mammalian smooth muscle. The difference in ease of penetration and length of holding of a resting potential of the dogfish muscle as compared with the Golfingia muscles with the same microelectrodes was striking and indicates differences in the mechanical properties of the membranes.

Some action potentials were recorded intracellularly during maintained tension (fig. $8 \mathrm{~g}, \mathrm{i}$ ), and in response to shocks (fig. 8 a, b, d). These were simple spikes 0.5 second in duration. They did not overshoot zero potential, but decreased as the observed resting potential decreased, presumably during withdrawal (fig. $8, \mathrm{~d}$, e, f). They resembled the intracellular spikes of many mammalian smooth muscles.

\section{DISCUSSION}

The three muscles considered above have fibers of similar size and shape, yet they represent three different methods of propagation of activity. In the phascolosoma proboscis retractor, conduction is entirely by nerves and the electrical responses of the muscle fibers appear to be junction-type potentials. Nerve conduction has been indicated in non-striated muscles of holothurians, annelids, molluscs and coelenterates (Prosser, '59 for references). It is probable that all somatic non-striated muscles of invertebrates are activated by nerves. This is one important reason for avoiding the term smooth muscles for these short-fibered invertebrate muscles.

In the spindle muscle or intestinal retractor of phascolosoma, unlike the proboscis retractor, conduction is independent of nerves but is by mechanical pull from one region to the next. This muscle is excited to graded responses by quick stretches and is unusually sensitive to mechanical stimulation. The proboscis retractor, in contrast, responds passively to stretch much like striated muscle. The active response of the spindle muscle is direct rather than reflex. Why the fiber membranes of this muscle are so sensitive to mechanical deformation while those of the proboscis retractor are not, is an unsolved problem.

The dogfish mesenteric muscle or spiral valve retractor has properties like those of visceral smooth muscles of mammals. The velocity, absence of nerve impulses, insensitivity to nerve blocking drugs agree in indicating conduction from fiber to fiber through the muscle. Conduction passes a region of mechanical block as in cat intestinal muscle (Sperelakis and Prosser, '59). The dogfish muscle, however, does respond actively to mechanical stretch as does the chick amnion. The nature of the conduction process in smooth muscle is not fully known, but there appears to be electrical continuity between fibers. In no invertebrate non-striated muscle, somatic or visceral, has propagation of the vertebrate smooth muscle type been found.

The resting potentials of the dogfish smooth muscle are larger than those recorded for mammalian smooth muscle (50-60 $\mathrm{mv}$ in guinea pig taenia coli, Holman, '58). They contrast with the low values for the phascolosoma muscles. The differences may be due partly to true differences in resting potentials and partly to different mechanical properties of the cell surfaces making for variable shunting around the electrodes.

\section{SUMMARY}

1. The non-striated spindle muscle (intestinal retractor) of Golfingia (= Phascolosoma) gives single or repetitive responses to single shocks. Excitability is higher and tendency to rhythmic response is greater when the muscle is taut than when slack.

2. Quick stretch of the spindle muscle elicits fast action potentials and an active contraction, the magnitudes of which vary with amount of stretch and initial tension. Release of a contracted muscle is followed by redevelopment of tension.

3. Propagation is slow $(0.73 \mathrm{~cm} / \mathrm{sec}$ ond) and does not go beyond a region of mechanical block; there can be propaga- 
tion from one portion of muscle to another even when separated by a taut thread.

4. Tetracaine and D-tubocurarine, also storage in cold for 6 days fail to abolish propagated responses. No nerves were found in the muscles.

5. Penetration of the muscle fibers with microelectrodes proved very difficult, only small "resting potentials" were recorded and action potentials were graded.

6. The proboscis retractor of Golfingia shows passive elastic tension when stretched but no active response.

7. The mesenteric muscle (spiral valve retractor) of a dogfish may remain contracted for as long as several minutes in response to a single stimulus. Repetitive action potentials occur during contraction, there may be little or no electrical activity during maintenance of tension and renewed activity during relaxation.

8. The mesenteric muscle responds with an active contraction to quick stretch and redevelops tension after quick release during contraction.

9. Propagation is at $1.1 \mathrm{~cm} /$ second and passes a region of mechanical immobilization. Mechanical pull is not necessary for propagation. Nerve inactivating drugs (tetracaine, D-tubocurarine) failed to block propagation.

10. Penetration of the mesenteric muscle fibers was easier than with either of the Golfingia muscles; resting potentials averaged $70 \mathrm{mv}$. Intracellular action potentials were simple deflections without overshoot.

11. It is concluded that in these three non-striated muscles, propagation in the phascolosoma proboscis retractor is by nerves, in the spindle muscle propagation is by mechanical pull of one fiber on the next, and in the dogfish mesenteric muscle conduction is from muscle fiber to fiber much as in mammalian smooth muscle.

\section{LITERATURE CITED}

Andrews, E. A. 1890 Notes on the anatomy of Sipunculus gouldii, Pourtales. Studies from Biol. Lab. Johns Hopkins Univ., 4: 389-430.

Babkín, B. P., D. J. Bowie and J. V. V. Nicholls 1933 Structure and reactions to stimuli of arteries (and conus) in the elasmobranch genus, Raja. Contr. Canad. Biol. and Fish., N.S., 8: 207-225.

Bozler, E. 1948 Conduction, automaticity and tonus of visceral muscles. Experientia, 4: 213-218.

Bulbring, E. 1954 Membrane potentials of smooth muscle fibers of the taenia coli of the guinea pig. J. Physiol., 125: 302-315.

Cannon, W. B. 1908 The movements of the alimentary canal in the dogfish. Amer. Nat., 42: $326-327$.

Evans, D. H. L., and H. O. Schild 1956 Reaction of chick amnion to stretch and electrical stimulation. J. Physiol., 132: 31P.

Fisher, W. K. 1952 Sipunculid worms of California and Baja California. Proc. U. S. Nat. Mus., 102: $371-450$.

Holman, M. E. 1958 Membrane potentials recorded with high-resistance micro-electrodes; and the effects of changes in ionic environment on the electrical and mechanical activity of the smooth muscle of the taenia coli of the guinea pig. J, Physiol., 14: 464-488.

McKay-Sawyer, M. E. 1933 A mechanism controlling movement of the spiral intestine in elasmobranchs. Contr. Canad. Biol., 7 : 479-494.

Prosser, C. L. 1959 Comparative physiology of neuromuscular transmission with particular emphasis on non-striated muscles. In: Muscle, ed. G. Bourne, Academic Press, New York, 1960.

Prosser, C. L., and C. E. Melton 1954 Nervous conduction in smooth muscle of Phascolosoma proboscis retractors. J. Cell. and Comp. Physiol., 44: 255-276.

Prosser, C. L., C. E. Smith and C. E. Melton 1955 Conduction of action potentials in the ureter of the rat. Am. J. Physiol., 181: $651-660$.

Prosser, C. L., and N. Sperelakis 1956 Transmission in ganglion-free circular muscle from the cat intestine. Am. J. Physiol., 187: $536-545$.

- 1959 Electrical evidence for dual innervation of muscle fibers in the sipunculid Golfingia (=Phascolosoma). J. Cell. and Comp. Physiol., 54: 129-134.

Sperelakis, N., and C. L. Prosser 1959 Mechanical and electrical activity in intestinal smooth muscle. Am. J. Physiol., 196: 850-856. 